\title{
Glucocorticoid effects on insulin- and IGF-I-regulated muscle protein metabolism during aging
}

\author{
D Dardevet, C Sornet, I Savary, E Debras, P Patureau-Mirand \\ and J Grizard
}

Unité d'Etude du Métabolisme Azoté, Institut National de la Recherche Agronomique, 63122 Ceyrat, France

(Requests for offprints should be addressed to D Dardevet)

\begin{abstract}
This study was performed to assess the effect of glucocorticoids (dexamethasone) on insulin- and IGF-I-regulated muscle protein metabolism in adult and old rats. Muscle atrophy occurred more rapidly in old rats, and recovery of muscle mass was impaired when compared with adults. Muscle wasting resulted mainly from increased protein breakdown in adult rat but from depressed protein synthesis in the aged animal. Glucocorticoid treatment significantly decreased the stimulatory effect of insulin and IGF-I on muscle protein synthesis in adult rats by 25.9 and $58.1 \%$ respectively. In old rats, this effect was even greater, being $49 \cdot 3$ and $100 \%$ respectively. With regard to muscle
\end{abstract}

proteolysis, glucocorticoids blunted the anti-proteolytic action of insulin and IGF-I in both age groups. During the recovery period, adult rats reversed the glucocorticoidinduced resistance of muscle protein metabolism within 3 days, at which time old rats still exhibited the decrease in insulin-regulated proteolysis. In conclusion, the higher sensitivity of old rat muscle to glucocorticoids may in part result from the greater modification of the effects of insulin and IGF-I on muscle protein metabolism. These responses to glucocorticoids in old rats may be associated with the emergence of muscle atrophy with advancing age.

Journal of Endocrinology (1998) 156, 83-89

\section{Introduction}

During aging, a progressive loss of muscle mass has been described for both humans (Forbes 1976) and rodents (Klitgaard et al. 1989, Holloszy et al. 1991). This loss of protein results from an imbalance between rates of protein synthesis and degradation. This imbalance is not obvious when basal rates of protein turnover are measured (Dujovne \& Azarnoff 1975, Makrides 1983, El Haj et al. 1986, Goldspink et al. 1987), but can be detected in rats during the postprandial period or endurance training (Mosoni et al. 1995). We hypothesized that glucocorticoids may be involved in the emergence of muscle atrophy with advancing age. We first reported an increased sensitivity of muscle protein turnover to dexamethasone (DEX) with aging, which may create a slight but continuous imbalance between muscle protein synthesis and breakdown. In addition, we demonstrated that glucocorticoid action on skeletal muscle protein turnover differed markedly between adult and old rats and clearly showed that the recovery of muscle mass after such treatment was impaired in old rats and may result in muscle atrophy, especially when another stress situation is initiated before muscle mass recovery is complete.

Glucocorticoids are known to be potent diabetogenic agents resulting from both hepatic and peripheral resist- ance to the action of insulin (Amatruda et al. 1985). It is now well known that the action of insulin on muscle glucose uptake (Weinstein et al. 1995), glycogen synthesis (Leighton et al. 1987) and proteolysis (Louard et al. 1994) are reduced after glucocorticoid treatment. The mechanisms by which steroids alter insulin action on skeletal muscle remain unclear. Indeed, in skeletal muscle, the first cellular events involved in the action of insulin, i.e increase in insulin receptor number (Block \& Buse 1989, Giorgino et al. 1993, Saad et al. 1993), insulin receptor autophosphorylation (Block \& Buse 1989, Saad et al. 1993) and tyrosine phosphorylation of insulin receptor substrate-1 (IRS-1) (Giorgino et al. 1993, Saad et al. 1993), are not modified by glucocorticoid treatment. Only a decrease in the association/activation of phosphatidylinositol 3-kinase with IRS-1 in response to insulin has been recorded in young rats (Giorgino et al. 1993, Saad et al. 1993). Thus glucocorticoid-induced muscle atrophy may result from both the steroid effect per se and modification of insulin action on protein metabolism. On the basis of these observations, we hypothesized that the hypersensitivity of old rats to steroids and their inability to restore their muscle protein mass rapidly may result in part from both greater and longer-lasting glucocorticoid modification of anabolic hormones such as insulin and insulin-like growth factor-I (IGF-I). To substantiate this hypothesis, the effect 
of DEX on the insulin and IGF-I control of protein turnover in adult and old rats was studied in vitro in epitrochlearis muscles.

\section{Materials and Methods}

\section{Chemicals}

L- $\left[\mathrm{U}_{-}{ }^{14} \mathrm{C}\right]$ Phenylalanine $(450 \mathrm{mCi} / \mathrm{mmol})$ was obtained from Amersham (Aylesbury, Bucks, UK). Porcine insulin and recombinant human $\left[\mathrm{Thr}^{59}\right]$-IGF-I were purchased from Novo (Bagsvaerd, Denmark) and Preprotech (Paris, France). All other reagents were obtained from Sigma Chemical Co. (St Louis, MO, USA).

\section{Animals}

Adult (6-8 months) and old (18 months) male SpragueDawley rats were purchased from Iffa-Credo (L'Arbresle, France) and housed under controlled environmental conditions (temperature $22{ }^{\circ} \mathrm{C} ; 12 \mathrm{~h}$ dark period starting at $1800 \mathrm{~h}$ ). They were given free access to commercial laboratory chow and water before the experiments were performed. Both adult and old rats were randomly divided into a control and a DEX-treated group. DEX (a synthetic glucocorticoid analogue that does not bind to plasma binding proteins) was given daily (at $0900 \mathrm{~h}$ ) via the drinking water. DEX concentration was adjusted every day on the basis of drinking water intake the day before. Adult and old animals received $508 \pm 87$ and $541 \pm$ $98 \mu \mathrm{g} / \mathrm{kg}$ per day respectively. DEX was given for 5 days in old rats but for 6 days in adults to generate a similar degree of muscle atrophy in the two groups, since muscle wasting was more rapid in aged animals (Dardevet et al. 1995). Rats were allowed to recover for either $3(R+3)$ or $7(\mathrm{R}+7)$ days. As DEX has been reported to decrease food intake, all groups were pair-fed to the group that had the lowest food intake (i.e DEX-treated old rats). Animals were killed under anesthesia with sodium pentobarbital $(6.0 \mathrm{mg} / 100 \mathrm{~g}$ body weight) after an overnight fast. Blood samples were collected for glycemia assessment and for measuring plasma insulin levels. Epitrochlearis muscles were dissected intact for incubation.

\section{Muscle incubation}

On the day of the experiment, the skin on the fore limb was removed and the epitrochlearis muscle was excised and rinsed in ice-cold Krebs-Henseleit bicarbonate buffer $\left(\mathrm{NaCl} 120 \mathrm{mM}, \mathrm{KCl} 4.8 \mathrm{mM}, \mathrm{NaHCO}_{3} 25 \mathrm{mM}, \mathrm{CaCl}_{2}\right.$ $2.5 \mathrm{mM}, \mathrm{KH}_{2} \mathrm{PO}_{4} 1.2 \mathrm{mM}$ and $\mathrm{MgSO}_{4} 1.2 \mathrm{mM}$, pH 7.4, supplemented with $5 \mathrm{mM}$ HEPES, $0.17 \mathrm{mM}$ leucine, $0.20 \mathrm{mM}$ valine, $0 \cdot 10 \mathrm{mM}$ isoleucine, $0 \cdot 1 \%$ BSA $(99 \%$ fatty acid free)). Muscles were then transferred to plastic tubes containing $2 \mathrm{ml}$ buffer saturated with $95 \% \mathrm{O}_{2} / 5 \%$
$\mathrm{CO}_{2}$ gas mixture and preincubated for $30 \mathrm{~min}$. The effect of insulin and IGF-I was then assessed by incubating the muscles in fresh medium of the same composition supplemented with or without $30 \mathrm{nM}$ hormone for $2 \mathrm{~h}$. Incubation was continued for a further hour in fresh medium containing $0.5 \mathrm{mM} \mathrm{L}-\left[{ }^{14} \mathrm{C}\right]$ phenylalanine $(0 \cdot 15 \mu \mathrm{Ci} / \mathrm{ml})$. At the end of the incubation, incubation medium was frozen at $-20{ }^{\circ} \mathrm{C}$ until assay, and muscles were blotted and homogenized in 10\% trichloroacetic acid (TCA). Samples were centrifuged at $10000 \mathrm{~g}$ for $10 \mathrm{~min}$ at $4{ }^{\circ} \mathrm{C}$ and TCA-insoluble material was washed three times with $10 \%$ TCA. The resultant pellet was solubilized in $1 \mathrm{M}$ $\mathrm{NaOH}$ at $37^{\circ} \mathrm{C}$ for determination of protein and radioactivity incorporated into muscle protein. Tissue protein mass was determined using the bicinchoninic acid procedure (BCA; Pierce Chemical Co., Rockford, IL, USA), and protein-bound radioactivity was measured using scintillation counting. Protein synthesis was calculated by dividing the protein-bound radioactivity by the specific radioactivity of the phenylalanine in the incubation medium. It was expressed as nmol phenylalanine incorporated $/ \mathrm{mg}$ protein per $\mathrm{h}$. Protein degradation was determined as described by Tischler et al. (1982). Because tyrosine is neither synthesized nor degraded by muscle, the release of this amino acid from muscle into the incubation medium directly reflects net protein breakdown. Proteolysis was then estimated by the sum of net tyrosine release into the incubation medium and protein synthesis after conversion of the rate of phenylalanine incorporation into proteins into tyrosine equivalents (Tischler et al. 1982). Protein degradation was expressed as nmol tyrosine/mg protein per $\mathrm{h}$.

\section{Statistical analysis}

Data are expressed as mean \pm S.E.M. or mean \pm S.E.M. of the absolute difference between values from pair-fed control and DEX-treated animals of the same age. Statistical evaluation of the data was performed using Student's $t$-test or a two-way ANOVA for each age, with treatment and stage as the main factors. The effects of these factors were tested at each stage by the Fischer posteriori test of comparison of means, and were considered significant when $P<0 \cdot 05$.

\section{Results}

\section{Animal characteristics}

At the end of the DEX treatment, epitrochlearis muscle atrophy was similar in adult and old rats $(-30 \cdot 0 \pm 11 \cdot 2$ and $-26 \cdot 5 \pm 10 \cdot 2 \mathrm{mg}$ respectively) (Fig. 1). As we have previously shown, old rats are more sensitive to glucocorticoids than adults, as similar muscle atrophy was generated with a shorter treatment period (5 vs 6 days). After 3 days 


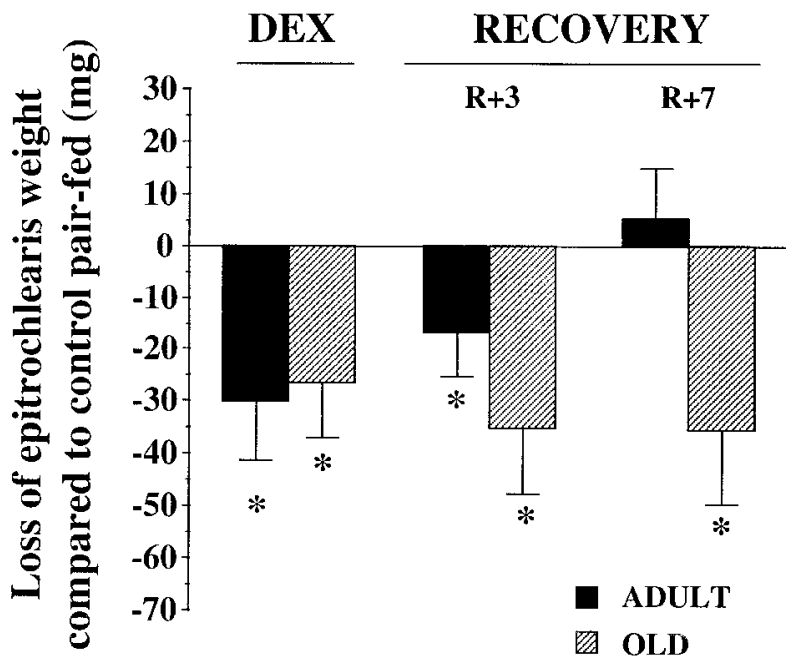

Figure 1 Loss of epitrochlearis muscle mass in adult and old rats during DEX treatment and subsequent recovery, compared with control pair-fed animals. Values are means for 14-16 animals. Vertical bars denote S.E.M. ${ }^{*} P<0 \cdot 05$ vs control pair-fed values.

of DEX withdrawal, epitrochlearis mass increased in adult rats but was still significantly lower $(-16 \cdot 7 \pm 8 \cdot 4 \mathrm{mg})$ than in control pair-fed animals. In contrast, muscle atrophy continued in the old rats $(-35 \cdot 2 \pm 12 \cdot 2 \mathrm{mg}$; $P<0 \cdot 05)$ (Fig. 1). Adult rats had normalized their epitrochlearis mass after 7 days of recovery, whereas old rats still exhibited marked muscle atrophy $(-35.4 \pm 14.3 \mathrm{mg}$; $P<0 \cdot 05)$ when compared with pair-fed controls (Fig. 1). At the end of the DEX treatment, both adult and old rats showed a significant increase in blood glucose when compared with their pair-fed controls $(3 \cdot 46 \pm 0 \cdot 44$ vs $1.70 \pm 0.08 \mathrm{~g} / 1$ in adult and $4.94 \pm 0.35$ vs $1.68 \pm 0.08 \mathrm{~g} /$ 1 in old rats; $P<0 \cdot 05)$. This hyperglycemia was associated with hyperinsulinemia $(203 \pm 20$ vs $35 \pm 10$ and $235 \pm 37$ vs $49 \pm 7 \mu \mathrm{U} / \mathrm{ml}$ in adult and old rats respectively; $P<0 \cdot 05)$.

\section{Basal protein synthesis and degradation}

DEX-induced muscle atrophy in adult rats resulted from increased proteolysis $(+36.5 \% ; P<0.05)$ without any significant modification of the rate of protein synthesis (Fig. 2). In contrast, in old rat muscle, loss of muscle mass resulted from depressed protein synthesis $(-25 \cdot 8 \%$; $P<0.05)$ along with slightly increased proteolysis $(+16.9 \%)$ (Fig. 2). After DEX withdrawal, adult muscle proteolysis returned to control values whereas protein synthesis was progressively stimulated $(+19 \cdot 3 \%$ and $+64 \cdot 4 \%$ vs controls at $\mathrm{R}+3$ and $\mathrm{R}+7$ respectively; $P<0 \cdot 05$ ) (Fig. 2 ). Old rats differed from adults in that muscle protein synthesis only returned to control levels and was not stimulated above this level. These observations are in agreement with the

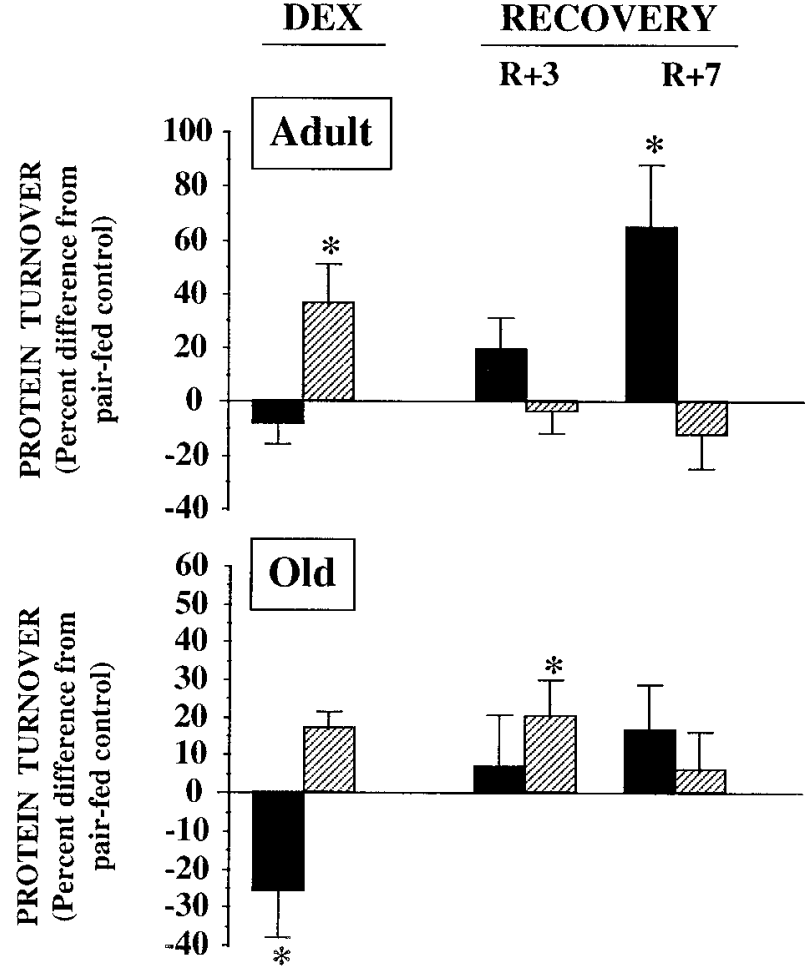

Figure 2 Basal muscle protein turnover in adult and old rats during DEX treatment and subsequent recovery. Epitrochlearis muscles from adult and old rats were excised and incubated in vitro as described in Materials and Methods. Rates of protein synthesis (solid bars) were measured by determining incorporation of $\left[{ }^{14} \mathrm{C}\right]$ phenylalanine into muscle proteins. Rates of proteolysis (hatched bars) were estimated simultaneously with the rates of protein synthesis as the sum of net release of tyrosine into the incubation buffer over $1 \mathrm{~h}$ and the amount of tyrosine equivalents incorporated into muscle protein during the same time interval. Values are expressed as percentage differences from pair-fed controls and are means \pm S.E.M. for 5-11 muscles in each group. ${ }^{*} P<0.05$ vs control pair-fed values.

delayed recovery of muscle protein mass in old rats compared with adult animals.

Insulin and IGF-I responsiveness of muscle protein turnover in the presence of DEX

As expected, insulin and IGF-I significantly stimulated $(P<0 \cdot 05)$ muscle protein synthesis in pair-fed control adult rats $(0 \cdot 135 \pm 0 \cdot 005$ and $0 \cdot 126 \pm 0 \cdot 014$ vs $0 \cdot 075 \pm$ $0.004 \mathrm{nmol}$ phenylalanine/mg protein per h respectively; $P<0 \cdot 05$ vs basal) (Fig. 3). When adults were treated with DEX, both hormones were still able to stimulate protein synthesis but to a lesser extent than in pair-fed controls. Indeed, the incremental increase in protein synthesis above basal due to the effect of insulin and IGF-I only represented 74.1 and $41.9 \%$ of the corresponding values in the pair-fed control group $(P<0 \cdot 05$ vs basal). Note that the 


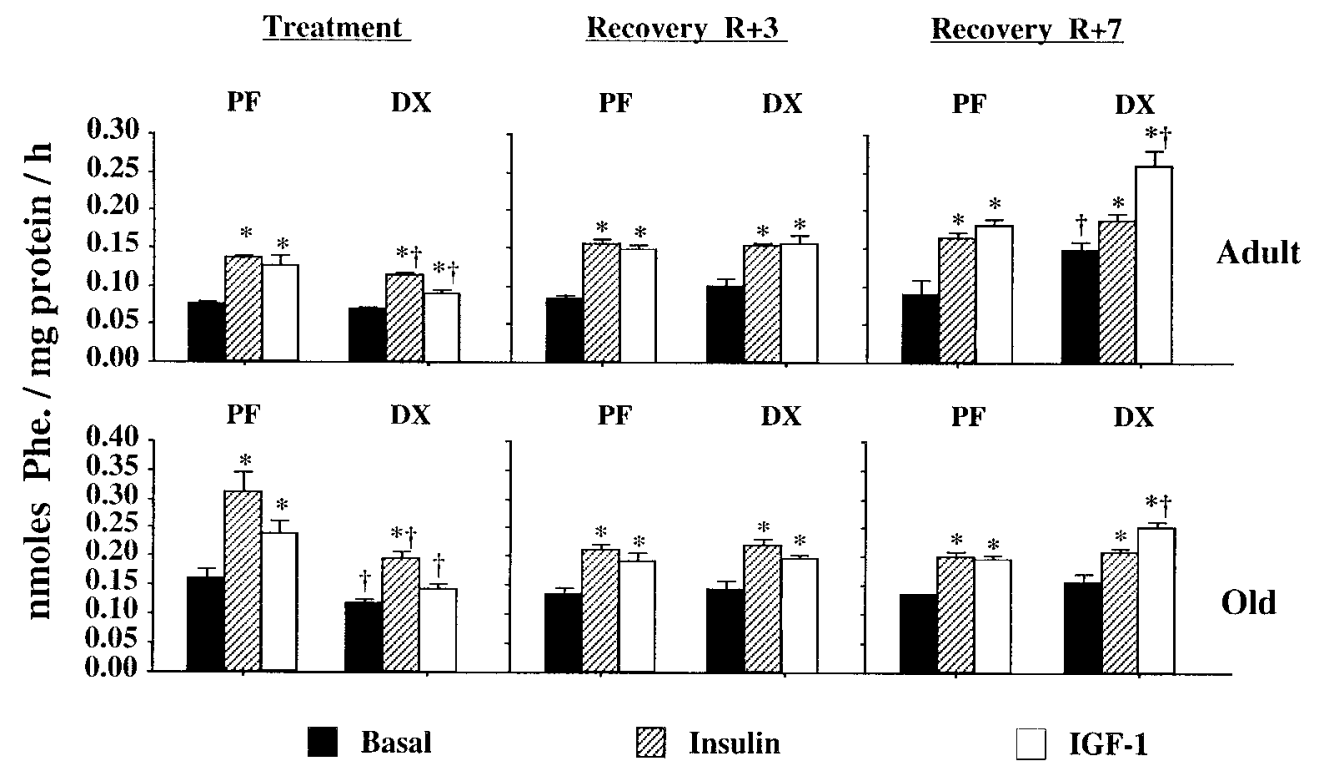

Figure 3 Effect of DEX (DX) and subsequent recovery on the responsiveness of muscle protein synthesis to insulin and IGF-I in adult and old rats. Epitrochlearis muscles from adult and old rats were excised and incubated in vitro as described in Materials and Methods. Values shown are means \pm S.E.M. for $4-13$ muscles in each group. ${ }^{*} P<0.05$ vs basal values from the same group; $+P<0.05$ vs the value recorded in the pair-fed group (PF).

impairment in hormone responsiveness after DEX treatment was more pronounced with IGF-I than with insulin (Fig. 3).

Insulin and IGF-I also stimulated protein synthesis in pair-fed control old rats $(P<0.05$ vs basal) (Fig. 3). However, DEX treatment had a greater effect on muscle protein synthesis responsiveness to the hormones than in adults (Fig. 3). The effect of IGF-I was totally abolished and the effect of insulin, although significant $(P<0 \cdot 05$ vs basal), only represented $50.7 \%$ of the value of pair-fed controls (reflected by the incremental increase of protein synthesis above basal).

Insulin significantly reduced the rate of proteolysis in epitrochlearis muscles from both adult and old control rats (i.e. $-21 \cdot 2 \%$ and $-15 \cdot 3 \%$ respectively; $P<0 \cdot 05$ ), but its effect was totally abolished when rats were treated with DEX (Fig. 4). IGF-I had no significant effect on muscle proteolysis whatever the age group of the rats (Fig. 4).

Insulin and IGF-I responsiveness of muscle protein turnover after DEX withdrawal

At $\mathrm{R}+3$ and $\mathrm{R}+7$, insulin stimulated protein synthesis in both pair-fed and treated muscles from both age groups, and the maximum response was not significantly different between control and DEX-treated animals at $\mathrm{R}+3$ and $\mathrm{R}+7$ (Fig. 3), showing that, in muscles from both adult and old rats, normal responsiveness of protein synthesis to insulin was restored within 3 days. When adult and old muscles were incubated in the presence of IGF-I, the maximum response of muscle protein synthesis at $\mathrm{R}+3$ was also similar in pair-fed and treated-rats (Fig. 3) but was higher in DEX-treated than in pair-fed controls at $\mathrm{R}+7$ in both age groups (i.e. $+44 \cdot 4$ and $+29 \cdot 4 \%$ in adult and old rats respectively; $P<0 \cdot 05)$.

In the presence of either insulin or IGF-I, rates of muscle proteolysis were not significantly different between controls and treated adults at $\mathrm{R}+3$ and $\mathrm{R}+7$ (Fig. 4), showing that, in adult rats, normal responsiveness of muscle proteolysis to both hormones was restored within 3 days. In contrast, in old rats, the maximum response of muscle proteolysis recorded in the presence of insulin was still significantly increased in the DEX-treated animals compared with controls (Fig. 4). When decremental decrease under basal values was considered, old DEXtreated rats still exhibited a significant $21.9 \%$ reduction in responsiveness of muscle proteolysis to insulin. The rate of proteolysis regulated by insulin and IGF-I was no longer significantly different between the DEX-treated and control old rats at $\mathrm{R}+7$ (Fig. 4).

\section{Discussion}

As reported previously (Dardevet et al. 1995), DEX induced skeletal muscle protein wasting in both adult and old rats. A similar degree of atrophy was, however, generated with a shorter treatment period in old rats, suggesting increased sensitivity to glucocorticoids with aging. As muscle atrophy results from an imbalance 


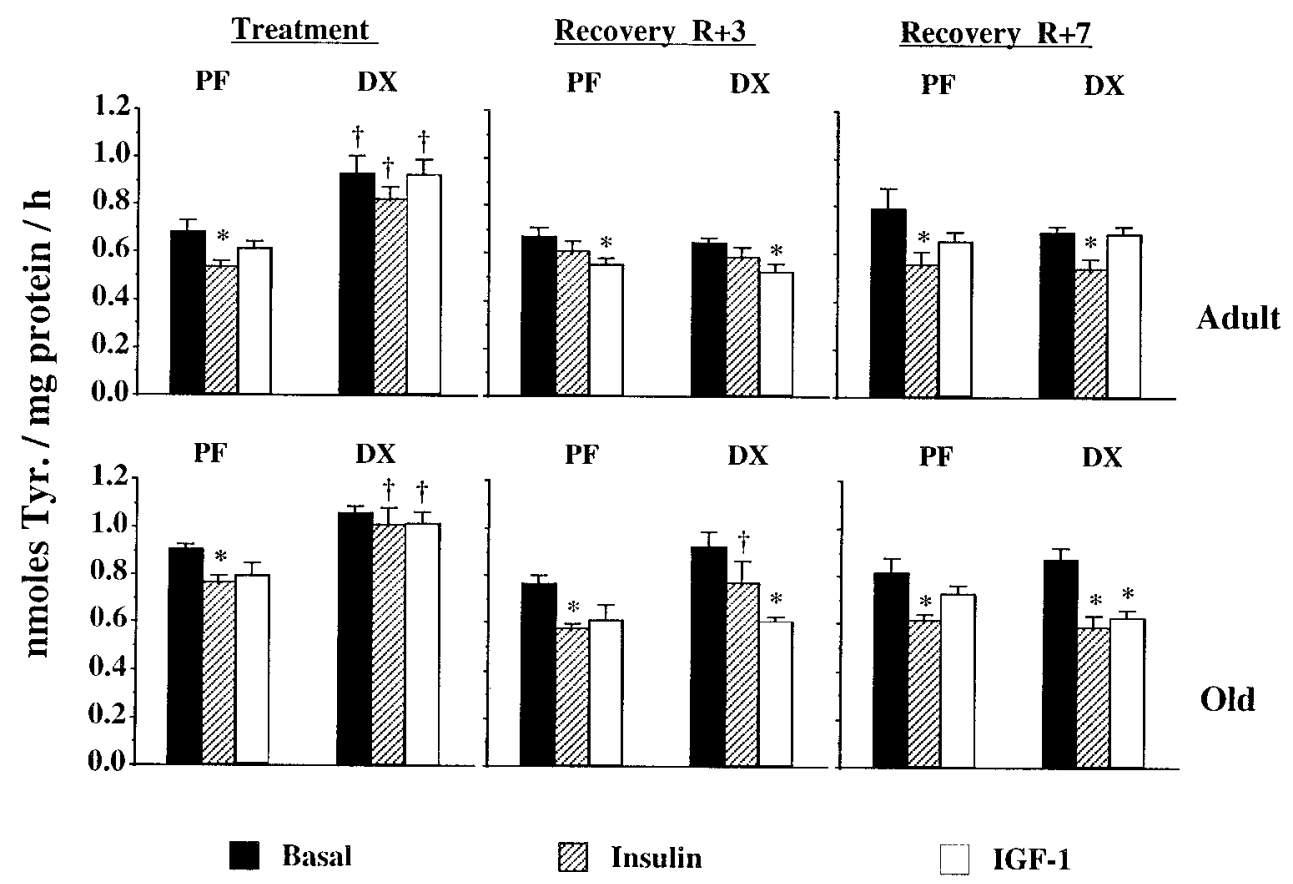

Figure 4 Effect of DEX (DX) and subsequent recovery on the responsiveness of muscle protein degradation to insulin and IGF-I in adult and old rats. Epitrochlearis muscles from adult and old rats were excised and incubated in vitro as described in Materials and Methods. Rates of proteolysis were measured as described in Fig. 2. Values shown are means \pm S.E.M. for $4-12$ muscles in each group. ${ }^{*} P<0 \cdot 05$ vs basal values from the same group; $\uparrow P<0.05$ vs the value recorded in the pair-fed group (PF).

between protein synthesis and degradation, a better knowledge of the regulation of these pathways is needed to understand this higher sensitivity to glucocorticoids in old rats. We here demonstrate that glucocorticoid treatment mainly increased protein degradation in adult rat muscle but mainly depressed protein synthesis in the aged rat muscle. These observations were made using epitrochlearis muscle incubated in the absence of any hormone. Thus their physiological relevance must be considered with caution since the well-known interactive effect of glucocorticoids and insulin on muscle protein turnover was not taken into account. Indeed, it has previously been shown that glucocorticoids alter the action of insulin on both protein synthesis (Odedra \& Millward 1982, Southorn et al. 1990) and proteolysis (Southorn et al. 1990) in muscle from young growing rats. Louard et al. (1994) also showed that DEX treatment antagonizes the anti-proteolytic action of insulin on human skeletal muscle. In contrast with the effects of insulin, the responsiveness of muscle protein metabolism to IGF-I under the influence of glucocorticoids has not been studied very extensively. Hellstern et al. (1996) found, however, that IGF-I failed to reverse the DEX-induced catabolic state in growing piglets, suggesting that protein metabolism became totally resistant to this hormone. Our study extends these findings to adult and old rats.
Our results clearly demonstrate that DEX treatment decreased the ability of insulin and IGF-I to stimulate protein synthesis in both adult and old rat muscles. However, the effect of the glucocorticoid was more pronounced in old than adult rats for both insulin (49.3 and $25.9 \%$ decreased responsiveness respectively) and IGF-I (100 and 58.1\% decreased responsiveness respectively). The consequence of this hormonal resistance is that the decrease in muscle protein synthesis between control pair-fed and DEX-treated old rats was more enhanced than in adults under insulin $(-37 \cdot 3 \%)$ and IGF-I $(-40 \cdot 3 \%)$ when compared with basal conditions $(-25 \cdot 8 \%)$. With regard to proteolysis, DEX treatment resulted in the abolition of the ability of insulin to inhibit muscle protein degradation in both adult and old rats. Thus, as for protein synthesis, the difference in proteolysis between control pair-fed and DEX-treated rats was higher in the presence of insulin $(+52.9$ and $+31.7 \%$ in adult and old rats respectively) or IGF-I $(+51.4$ and $+28.1 \%$ in adult and old rats respectively) than in their absence $(+36.5$ and $+16.9 \%$ in adult and old rats respectively). In conclusion, our results demonstrate that glucocorticoids may induce muscle protein wasting per se, but the effect may also be the result of the decreased in vivo anabolic effect of both insulin and IGF-I in old and adult rats. Compared with that in adults, the higher 
resistance of old rat muscles to both hormones could also explain their higher sensitivity to DEX in generating muscle protein wasting. This was not so clearly demonstrated when basal muscle protein turnover only was considered.

Glucocorticoids are known to be potent diabetogenic agents associated with marked hyperinsulinemia. Since DEX-induced insulin resistance was less pronounced in adult than old rats, it might be hypothesized that the DEX-induced increase in plasma insulin levels may reverse more efficiently the effect of glucocorticoids on muscle protein synthesis in adult than in old rats. However, such a phenomenon cannot explain the in vivo hypersensitivity of old rats to glucocorticoids. Indeed, it has been shown that increased basal insulin levels failed to stimulate in vivo muscle protein synthesis in both adult and old rats (Mosoni et al. 1993), demonstrating that insulin at physiological levels already maximally stimulates muscle protein synthesis. Thus the hyperinsulinemia generated by DEX cannot counteract the effects of DEX on muscle protein synthesis, and the difference in insulin-stimulated protein synthesis that we observed in vitro should also be found in vivo. The effect of insulin on glucocorticoidinduced muscle protein wasting has also been studied in young growing rats. The results of the experiment of Southorn et al. (1990) agree with ours; they demonstrated that the responsiveness of muscle protein synthesis to insulin was altered when animals were treated with glucocorticoids and that insulin infusion in vivo did not counteract the decrease in muscle protein synthesis generated by corticosterone. In contrast, the study of Tomas et al. (1984) showed that, in diabetic rats treated with corticosterone, insulin replacement in vivo produced improved muscle protein synthesis in a dose-related fashion, suggesting that insulin was able to counteract the effect of the steroids. However, it is important to note that, in these experiments when induced insulinemia reached control values and above, insulin did not have any further beneficial effect on muscle protein synthesis, and the rate of muscle protein synthesis of diabetic rats treated with corticosterone and insulin remained low when compared with control rats. In other words, insulin was only able to counteract the effects of glucocorticoids on muscle protein synthesis in the range of physiological hypoinsulinemia. In contrast with their effect on insulin, glucocorticoids have been shown to depress plasma IGF-I levels (Tomas et al. 1992, Hellstern et al. 1996). Thus the DEX-induced IGF-I resistance could not be counteracted in vivo by a compensatory increase in IGF-I. Furthermore, the decrease in blood IGF-I in DEX-treated rats may generate in vivo lower protein metabolism responses than those we recorded in vitro with concentrations allowing maximum response. In this case, the glucocorticoid-induced IGF-I resistance would be greater in vivo than in vitro. Taken together, these findings indicate that the consequences of the DEX-induced IGF-I resistance of muscle protein metabolism could be more damaging in vivo than the defective insulin action.

The mechanisms by which glucocorticoids induce insulin and IGF-I resistance of skeletal muscle remain unclear. Studies investigating the first cellular events involved in insulin action showed that glucocorticoids decreased the association/activation of phosphatidylinositol 3-kinase with IRS-1 in response to insulin in young rat skeletal muscle (Giorgino et al. 1993, Saad et al. 1993), suggesting that glucocorticoids may induce muscle insulin resistance by altering this intracellular signalling pathway. On the other hand, Petrides et al. (1994) demonstrated that $24 \mathrm{~h}$ of mild hyperinsulinemia abolished the whole body anti-proteolytic action of insulin in humans. Thus we cannot exclude the possibility that, in our experiment, DEX may have also altered indirectly the insulin effect on muscle proteolysis by reaching its physiological level.

After DEX withdrawal, adult rats rapidly restored their muscle protein mass within 7 days, whereas old animals still showed a significant reduction of epitrochlearis mass. The recovery of muscle mass after this treatment was thus impaired in old rats. The basal protein metabolism study showed that, when compared with pair-fed controls, DEX-treated adults normalized their rates of protein synthesis and proteolysis within 3 days and had even increased the rate of protein synthesis at day 7 , whereas old rats did not show any increase in the rate of muscle protein synthesis. Thus adult rats showed a positive nitrogen balance within 7 days, whereas old rats only equilibrated it during this time period. These differences between old and adult rats in basal muscle protein turnover during the recovery period should be enhanced in the presence of hormones. Indeed (1) insulin-regulated proteolysis was still affected in old rats after 3 days of DEX withdrawal and (2) the hyper-responsiveness of protein synthesis to IGF-I in DEX-treated muscles was more marked in adult than in old rats 7 days after DEX withdrawal, allowing them to restore their muscle protein mass more efficiently in the presence of IGF-I. Taken together, these findings are consistent with a higher rate of muscle mass recovery in adult rats.

In conclusion, our study brings new insights into the effect of glucocorticoids on muscle atrophy and protein turnover in adult and old rats. The overall effect of glucocorticoid treatment resulted from both glucocorticoid action per se and insulin and IGF-I resistance of muscle protein turnover. Old rats were more sensitive to the treatment than adults. This was mainly due to the dramatic decrease in protein synthesis caused by the treatment in old animals particularly under hormonal regulation (proteolysis being affected whatever the age). Moreover, the recovery of muscle mass after glucocorticoid withdrawal was slow in old rats compared with adults. Accordingly, proteolysis remained at a high rate and resistant to the inhibitory effect of insulin in old rats. In contrast, protein synthesis increased and specifically showed a 
hyper-responsiveness to IGF-I in adult rats. These responses to glucocorticoids in old rats may help to explain the emergence of muscle atrophy with advancing age.

\section{References}

Amatruda JM, Livingston JN \& Lockwood DH 1985 Cellular mechanisms in selected states of insulin resistance: human obesity, glucocorticoid excess, and chronic renal failure. Diabetes/Metabolism Reviews 1 293-317.

Block NE \& Buse MG 1989 Effects of hypercortisolemia and diabetes on skeletal muscle insulin receptor function in vitro and in vivo. American Journal of Physiology 256 E39-E48.

Dardevet D, Sornet C, Taillandier D, Savary I, Attaix D \& Grizard J 1995 Sensitivity and protein turnover response to glucocorticoids are different in skeletal muscle from adult and old rats. Lack of regulation of the ubiquitin-proteasome proteolytic pathway in aging. Journal of Clinical Investigation 96 2113-2119.

Dujovne LA \& Azarnoff DL 1975 Clinical complications of corticosteroid therapy: a selected review. In Steroid Therapy, pp 27-41. Ed DL Azarnoff. Philadelphia: Saunders.

El Haj AJ, Lewis SEM, Goldspink DF, Merry BJ \& Holehan AM 1986 The effect of chronic and acute dietary restriction on the growth and protein turnover of fast and slow types of rat skeletal muscle. Comparative Biochemistry and Physiology 85A 281-287.

Forbes GB 1976 The adult decline in lean body mass. Human Biology 48 161-173.

Giorgino F, Almahfouz A, Goodyear LJ \& Smith RJ 1993 Glucocorticoid regulation of insulin receptor and substrate IRS-1 tyrosine phosphorylation in rat skeletal muscle in vivo. Journal of Clinical Investigation 91 2020-2030.

Goldspink DF, El Haj AJ, Lewis SEM, Merry BJ \& Holehan AM 1987 The influence of chronic dietary intervention on protein turnover and growth of the diaphragm and extensor digitorum longus muscles of the rat. Experimental Gerontology 22 67-78.

Hellstern G, Reijngoud DJ, Stellaard F \& Okken A 1996 Insulin-like growth factor-I fails to reverse corticosteroid-induced protein catabolism in growing piglets. Pediatric Research 39 421-426.

Holloszy JO, Chen M, Cartee GD \& Young JC 1991 Skeletal muscle atrophy in old rats: differential changes in the three fiber types. Mechanisms of Ageing and Development 60 199-213.

Klitgaard H, Brunet A, Maton B, Lamaziere C, Lesty C \& Monod H 1989 Morphological and biochemical changes in old rat muscles: effect of increased use. Journal of Applied Physiology 67 1409-1417.

Leighton B, Challiss RAJ, Lozeman PJ \& Newsholme EA 1987 Effects of dexamethasone treatment on insulin-stimulated rates of glycolysis and glycogen synthesis in isolated incubated skeletal muscles of the rat. Biochemical Journal 246 551-554.

Louard RJ, Bhushan R, Gelfand RA, Barrett EJ \& Sherwin RS 1994 Glucocorticoids antagonize insulin's antiproteolytic action on skeletal muscle in humans. Journal of Clinical Endocrinology and Metabolism 79 278-284.

Makrides SC 1983 Protein synthesis and degradation during ageing and senescence. Biological Reviews 58 343-422.

Mosoni L, Houlier ML, Patureau Mirand P, Bayle G \& Grizard J 1993 Effect of amino acids alone or with insulin on muscle and liver protein synthesis in adult and old rats. American Journal of Physiology 264 E614-E620.

Mosoni L, Valluy MC, Serrurier B, Prugnaud J, Obled C, Guezennec CY \& Patureau Mirand P 1995 Altered response of protein synthesis to nutritional state and endurance training in old rats. American Journal of Physiology 268 E328-E335.

Odedra BR \& Millward DJ 1982 Effect of corticosterone treatment on muscle protein turnover in adrenalectomized rats and diabetic rats maintained on insulin. Biochemical Journal 204 663-672.

Petrides AS, Luzi L \& DeFronzo RA 1994 Time-dependent regulation by insulin of leucine metabolism in young healthy adults. American Journal of Physiology 267 E361-E368.

Saad MJA, Folli F, Kahn JA \& Kahn CR 1993 Modulation of insulin receptor, insulin receptor substrate-1, and phosphatidylinositol 3-kinase in liver and muscle of dexamethasone-treated rats. Journal of Clinical Investigation 92 2065-2072.

Southorn BG, Palmer R.M \& Garlick PJ 1990 Acute effects of corticosterone on tissue protein synthesis and insulin-sensitivity in rats in vivo. Biochemical Journal 272 187-191.

Tischler ME, Desautels M \& Goldberg AL 1982 Does leucine, leucyl-tRNA, or some metabolite of leucine regulate protein synthesis and degradation in skeletal and cardiac muscle? Journal of Biological Chemistry 257 1613-1621.

Tomas FM, Murray AJ \& Jones LM 1984 Interactive effects of insulin and corticosterone on myofibrillar protein turnover in rats as determined by $N^{\tau}$-methylhistidine excretion. Biochemical Journal $\mathbf{2 2 0}$ 469-479.

Tomas FM, Knowles SE, Owens PC, Chandler CS, Francis GL, Read LC \& Ballard FJ 1992 Insulin-like growth factor-I (IGF-I) and especially IGF-I variants are anabolic in dexamethasone-treated rats. Biochemical Journal 282 91-97.

Weinstein SP, Paquin T, Pritsker A \& Haber RS 1995 Glucocorticoidinduced insulin resistance: dexamethasone inhibits the activation of glucose transport in rat skeletal muscle by both insulin- and noninsulin-related stimuli. Diabetes 44 441-445.

Received 30 May 1997

Accepted 26 August 1997 